\title{
Students' Subject Choice in Secondary Schools in Tanzania: A Matter of Students' Ability and Interests or Forced Circumstances?
}

\author{
Joyce Lazaro Ndalichako1, Aneth Anselmo Komba ${ }^{2}$ \\ ${ }^{1}$ National Examinations Council of Tanzania, Dar es salaam, Tanzania \\ ${ }^{2}$ School of Education, University of Dar es salaam, Dar es salaam, Tanzania \\ Email: indalichako@yahoo.com, kombandembeka@yahoo.com
}

Received May 2014

\begin{abstract}
This study aimed at providing answers to two key questions: 1) Which subjects are most preferred by students in secondary schools? 2) What are the reasons behind the students' interest, or lack thereof, in particular subjects? The study employed qualitative methodology using a multiple case study holistic design. The students in the studied schools served as the unit of analysis. The study involved a sample of 18 secondary schools that were purposefully selected. Data were collected using focus group discussions, observation and documentary review. The analysis involved the use of the Miles and Huberman's model of qualitative data analysis. The findings show that the majority of students in secondary schools preferred arts subjects notably because of the challenges they experience in learning science. The reasons for students preference of a particular subject included the inspiration from significant others, commitment and support provided by the subject teachers, the availability of teachers and their teaching approaches and relevance of the subject to their daily life experiences. On the basis of these findings, it is recommended that the government should create a conducive learning environment, especially for community secondary schools, that will allow students to select subjects on the basis of their ability and interests.
\end{abstract}

\section{Keywords}

Students' Subject Interest, Teaching Approaches, Learning Environment

\section{Introduction}

Students start secondary education with the expectations that the schools will provide them with an environment that will allow them to freely decide the subjects to study based on their abilities and interests. Interest in the subject is regarded as the most important motivational factor in learning [1]. Interest can be described as preference to engage in some types of activities rather than others. When interested in a particular phenomenon or activity, one is favorably inclined to attend to it and give time for it [2]. 
In Tanzanian context, students joining secondary schools are supposed to take nine subjects namely Mathematics, English, Kiswahili, Biology, Civics, Physics, Chemistry, Geography, and History. In their third year of schooling, students are allowed to select one of the following optional bias subjects: Science, Business, Agricultural Science, Technical and Home Economics subjects [3]. Thus, students opting to take science continue with Physics and Chemistry while those who are not opting for science bias could drop those subjects. Students are allowed to take a minimum of 7 and a maximum of 10 subjects. In some cases, the choice of the optional subjects taken is not purely a matter of students' decision. It all depends on the availability of such subjects in their school. Due to unavailability of teachers and insufficient teaching and learning facilities, some optional subjects are offered to a very small scale within a limited number of schools. To give an impression for this, Table 1 presents the number of students who sat for Certificate for Secondary Education Examination (CSEE) 2013 bias subjects out of a total of 362,062 candidates [4].

As shown in Table 1, the optional bias subjects that were taken by many students were Chemistry (40.9\%) and Physics (29.6\%). Business subjects (e.g., Commerce) were taken by only 6.2 percent whereas agricultural science was taken by only 2.9 percent of the candidates. Technical subjects and home economics related subjects constitute a minority of students opting for them.

Ideally, students are expected to select subjects that suit their interests and abilities. The learning experiences gained in Forms I and II serve as a basis for students in deciding which subjects to take in Form III. It is worth mentioning that secondary school education in Tanzania is the gateway to future career opportunities. The subjects selected by the students automatically dictate the kind of career paths they will enter upon graduation. Learning environment can play a significant role in determining students' preference for and attainment in a subject. Exemplary performance is attained in the teaching contexts where students are encouraged to work with each other and teachers are keen to guide them accordingly [5]. Similarly, [6] contended that good teaching involves effective communication and positive relationship with the students. It is expected that a teacher who develops a friendly teaching atmosphere will motivate students to engage in the subject even if they find it challenging. Hence, it is crucial to provide secondary school students with an environment that will allow them to pursue subjects that suit their interests and abilities. The provision of a favorable school environment enhances fairness and equity among students in terms of the quality of education they receive and in fulfilling their future needs and aspirations. This study sought to explore the subjects that students in secondary schools prefer to study and the reasons for their preferences.

\section{Research Methodology}

\subsection{Research Design}

The study employed a qualitative research methodology using a multiple case study holistic design [7]. The sample for this study involved 18 secondary schools that were selected using the purposive criterion and reputation case selecting sampling strategies [8]. The Focus Group Discussion (FGD) was the main data collection tool that was used to gather information used for the study. In each school the FGD involved 6 - 8 students. A total of 129 students were involved in the study.

\subsection{Study Area and Participants}

A criterion used to select schools was the pupils' performance in CSEE for the past three years. Based on that, a number of schools were selected, yet the final schools visited were those recommended by key informants in the

Table 1. Number of Students who sat for CSEE 2013 in selected option subjects.

\begin{tabular}{ccc}
\hline Subject & Reg. Candidates & \% of total candidates \\
\hline Chemistry & 150,010 & 40.9 \\
Physics & 108,609 & 29.6 \\
Engineering Science & 1219 & 0.3 \\
Agricultural Science & 10,777 & 2.9 \\
Commerce & 22,699 & 6.2 \\
Food and Nutrition & 1853 & 0.5 \\
\hline
\end{tabular}


studied regions such as the regional and district educational officers. Some of the schools that were identified by the researchers could not be reached because data collection was done during a heavy rain season that destroyed some of the roads infrastructure in the respective areas. The schools visited were classified into three groups. The first group consisted of three schools that had exemplary performance in CSEE for the past three years. One of these schools was a girls' private school and two were national secondary schools which admit students from various parts of the country. The second group consisted of 7 community schools that had satisfactory performance. In the context of this study, community schools, commonly known as ward secondary schools, are those established for the purpose of enrolling students from catchment areas that are within the same ward. Satisfactory performance was regarded as performance in which at least 50 percent of the students passed CSEE for the last three years. The third group comprised of 8 community schools with unsatisfactory performance in which less than 20 percent of the students passed CSEE for the past three years. The study involved mostly Form III and IV students.

\subsection{Data Collection and Analysis}

Data were collected mainly using FGD which lasted for a maximum of 30 minutes. All FGD sessions were tape recorded. With exception of two schools in which English language was used, all FGDs were held in Swahili. Other data collection methods involved documentary review and observation. FGD data were analysed using the Miles and Huberman Framework for data analysis. The analysis involved: verbatim transcription of recorded interviews followed by translation into English language; data reduction and compression without losing the key messages; data display, which entailed organizing the summarized information into data display sheets; and conclusion drawing and triangulation using data collected through observations and documentary review.

Since this study employed a case study design and purposive sampling strategies, its findings cannot be generalized to the population as a whole but only to the studied cases (case-to-case transfer) and may be transferred and applied in contexts similar to that used in this study [9].

\section{Findings}

The study intended to explore factors influencing students' interest in a particular subject. Through FGD with the students, a number of reasons that influence their interest in subjects were provided as presented in the following sub-sections.

\subsection{Inspiration from Significant Others}

Findings of the study show that inspiration from people who matters to the students play a significant role in influencing their interest for certain subjects. The following responses from students testify the role of inspiration to students' interests in the subjects.

I like mathematics because I have a lot of inspiration from different people like my father, my sister and other people around me. Some of them are engineers and I would love to become an engineer (FGD, student in school A, 27/2/2014).

I like mostly two subjects, the first one is mathematics. When I was a little kid, my parents used to tell me that mathematics is all about life, that everything is mathematics. Therefore, I was always eager to know more about mathematics. I found it wonderful. The second subject is chemistry...I want to be an engineer therefore I think Chemistry, Mathematics and Physics will help me to fulfil my dreams (FGD, student in school A, 27/2/2014).

I love all subjects but science subjects in particular. I personally like challenges, as I know that boys like to take science subjects, therefore I wish to compete with them and show that even girls can excel in science (FGD, student in school A, 27/2/2014).

The extracts indicate that students' interests in a particular subject were influenced by their parents and significant others. This finding is consistent with [10], who observed that the students' attitudes toward particular subjects are significantly determined by their parents' influence. However, in this study the influence of parents was not as pronounced as the influence of teaching and learning environment probably because of the nature of the schools involved in the study where most of the parents had not attained secondary education. On the other hand, eagerness to defy the common misconception that science subjects are for boys was also mentioned as a factor influencing some girls' decision to pursue science. 


\subsection{Commitment of Teachers and Their Teaching Approaches}

Teachers are instrumental in facilitating teaching and learning at school. Responses of students in the study show that teachers are key determinant factor in encouraging or discouraging students to engage in a subject and have a great influence on students' interests on the subject. Students explained attribute of teachers such as punctuality, friendliness, hardworking and effectiveness in teaching as some of the factors that make them like the subjects. The findings show that teachers who were not approachable and committed to their work eroded the motivation of students to pursue their subjects. The following are some of students' responses which indicate the role of teachers in influencing their preference for subjects:

I like Biology because our teacher is approachable. If a student does not understand something, he or she can follow the teacher who is very helpful..... (FGD, student, school B, 27/2/2014).

I like History because the teacher teaches well and does not miss lessons. When we were in Form III we finished all the topics and started some of Form IV topics. Also the teacher provides sufficient exercises which makes us understand the subject well and after marking the teacher makes corrections in the areas that most of us could not give correct answers (FGD, student, school F, 19/2/2014).

I like Chemistry and Biology. Although there is only one teacher in this school for those subjects, the teacher is highly committed and teaches us well (FGD, student, school D, 18/2/2014).

I like Physics because the teacher taught us well using a number of reference books. I can now solve almost all Physics questions comfortably. Indeed I am confident that there is no question which I will not be able to solve in the national examination (FGD, student, school B, 27/2/2014).

The findings confirm the role of teachers in influencing students' interests to learn a particular subject. This is consistent with the study by [11] which showed that teachers were able to influence the motivation of students via specific aspects of their teaching but mainly through their orientation to the student. On the other hand, some students indicated that they dislike certain subjects because they were disappointed by their teachers:

I don't like Chemistry because the teacher does not use interactive teaching methods. The teacher simply presents materials without checking whether students are following or not. If students ask questions, the teacher just ignores them and sometimes abusive words are used to discourage questions (FGD, student, school R, 15/4/2014).

I don't like Chemistry and Geography. The Chemistry teacher is harsh when teaching and does not elaborate the concepts very well. The Geography teacher insults students. One day the teacher asked a question and told one of us to respond. The student was unable to respond correctly so the teacher grabbed the student and told him that "your head is full of milk" (FGD, student, school K, 24/2/2014).

I don't like Kiswahili because the teacher tells us to copy notes from our colleagues who are in Form IV. In few occasions that the teacher teaches us, we don't understand the way he is teaching. If we ask questions, he discourages us by using abusive language (FGD, student, school J, 26/2/2014).

I don't understand the way our Geography teacher is teaching and I really fear the teacher. He likes to ask question and expects to get spontaneous answers. Now before you have even thought of the answer the teacher gives you strokes. I do not understand the subject and I feel that the use of corporal punishment in such a situation is unacceptable. You know sometimes we students tend to forget what we were taught in the past. Now before we even start recalling we are already punished and blamed for failure to understand the subject. This situation makes me hate the subject (FGD, student, school K, 24/2/2014).

The findings show that teaching approaches have strong impact on students' interest in the subject. This is consistent with [12] who contended that what happened in the classroom has impact on students' opportunity to learn. Thus effective teachers enhance opportunities for their students to learn while teachers with poor teaching approaches limit the opportunities for their students to learn a subject.

\subsection{Relevance of the Subject to Real Life Situation}

The findings show that students' value attached to particular subjects is related to the extent to which the subject is relevant and applicable to their real life situation. Students like subjects which enable them to obtain skills and knowledge to help them in their day to day activities. Notably, subject with irrelevant contents are difficult to follow and understand. This forces students to memorize concepts, which lead to their tendency to dislike those subjects. The students asserted the following in relation to the relevance of the subjects:

I like Biology because it enables me to understand myself and other living things (FGD, student, school C, 
20/2/2014).

I don't like History because it does not make sense to study things about my grandfathers which are not related to the life we are living at this time-we are taught things of the past which requires cramming than understanding. For me History has little relevance to my life (FGD, student, school B, 27/2/2014).

I love biology because it relates to real life situation and what I learn is applicable in life. We have a good biology teacher, who teaches well. Also, there are sufficient books in the library and it is the subject that I do well (FGD, student, school B, 27/2/2014).

\subsection{Availability of Teaching and Learning Materials}

Availability of teaching and learning materials was also mentioned as an essential factor in determining students' interests in the subject. Some of the students' responses are as follows:

Sincerely speaking, we are enjoying studying arts subjects. There is a serious shortage of science teachers, there are no textbooks in some subjects. For instance there is no physics textbook to the extent that even the teacher borrows a book from the students. Also, our science laboratory lacks the facilities that would allow us to conduct experiments. We don't do practical seriously, we are only swindling (FGD, student, school P, 17/4/2014).

I don't like science subject because in our school we have a shortage of science teachers. For instance we have only one Chemistry teacher who teachers all the classes from Form I to Form IV. So the teacher cannot teach effectively. The other challenge we have is lack of science laboratory equipment and chemicals. In some cases you can be in a laboratory doing say a food test practical and then you are told there are no chemicals for testing starch (FGD, School D, 18/2/2014).

I don't like science subjects because we are learning theoretically, we don't do any real practical work. There is what is called alternative to practical which is really confusing us. The teacher will come and tell you if you mix hydrogen peroxide with manganese two oxides you will see a mixture with certain colour, but if we had apparatus and chemicals we could have done this on our own and observe what will happen. So we are not doing practical but we get narrations of what will happen if you do a certain experiment (FGD, school E, 18/2/2014).

The students highlighted that lack of textbooks, laboratory facilities and science chemicals were among the factors that made them dislike the respective subjects. The literature maintains that the school plays a significant role when it comes to issues related to students' subject choice. The availability of resources in schools dictates students' choice of particular subjects [13]. It can therefore be inferred that resources availability in schools contributes to students' interests in a subject.

\subsection{Availability of Teachers}

During the study, it was revealed that students' interests in a subject can be affected by the school circumstances. It was noted that there is a scarcity of teachers in some schools which affect students' subject choice. The following are a few of the many responses given by students who participated in the study:

I don't like science subjects because there are no science teachers in our school. The lack of teachers demotivates us to take these subjects. We end up dropping science subjects. In some cases, students who take these subjects have to rely on their friends who receive tuition from other schools. They end up learning very little and hence fail to understand the subject to the desirable level of attainment (FGD, student, school K, 24/2/2014).

The subject that I am uncomfortable with is Chemistry because our school has no chemistry teacher. We didn't learn Chemistry in forms I to III. Recently, we got a Chemistry teacher but we're already in form IV. I'm wondering how can a teacher manage to teach all of the classes from Form I to IV, considering that every class has two streams (FGD, student, school M, 14/4/2014).

I like science subjects yet I have dropped them. The school has a serious shortage of science teachers and there are no science laboratories and apparatus. Teachers are unable to prepare and teach us how to conduct practical. They are only teaching theoretically (FGD, student, school I, 17/2/2014).

The findings further show that students lost interest or have dropped a certain subject because they did not have teachers. The following extracts indicate the situation:

I can say that I do not like Chemistry because our teacher was on study leave and we did not have any other Chemistry teacher in school. So, having stayed for one year and a half without a teacher has made me lose in- 
terest in the subject. Although the teacher is back, he is still the only teacher in school and is supposed to teach all the classes from Form I to Form IV. So it is really difficult for him to teach all of us effectively. The teacher cannot afford giving us sufficient exercises and assisting individual students who might need further assistance (FGD, student, school K, 24/2/2014].

I don't like mathematics. When I started secondary school Form I used to like Mathematics and I was doing very well. Unfortunately the teacher who was teaching us passed away and we did not get a replacement teacher. So the whole of second term in Form I we did not study mathematics. When we started form II the teacher we had did not care about our background, and started straight with the form II topics. So I found that there was a gap in my learning as we had not completed Form I syllabus and I started hating the subject. I could not understand what the teacher was doing, expecting us to understand the latter topics before the previous ones (FGD, school E, 18/2/2014).

I don't like Biology and Mathematics because we have no teachers for those subjects. Even if you try to study on your own you really reach a point where you cannot cope and you just give up. Even if you seek help from fellow students who attended tuition they only help to some extent but they cannot substitute the role of a teacher (FGD, student, school I, 17/2/2014).

The lack of science teachers was further confirmed in the school records. Some schools did not even have a single teacher for some science subjects. Furthermore, in the most of the schools visited, there were either one or two teachers for the whole school. The shortage of science teachers is a national problem. For example in 2013 the Government employed a total of 14,060 teachers in secondary schools, but only 2,014 of these (14\%) were science teachers. There is a nationwide shortfall of 37,130 teachers in secondary schools and most of them 26,948 (73\%) are science teachers. The critical shortage of science teachers has serious implications in terms of the effectiveness of teaching those subjects in schools.

\subsection{Language of Instruction}

Language of instruction was among the factors that encouraged students to like or dislike a particular subject. Students indicated that the use of English language limits their level of understanding of the concepts and hence made them dislike the subject. Students indicated that they liked subject in which the language was clear to them. The following are some of students' responses in relation to the language of instruction:

The biggest challenge here at our school is mainly English language. Our English language proficiency is very low and teachers are not doing anything to help us! Teachers have not implemented the English speaking policy which requires students to speak English. They use Kiswahili in teaching but students cannot use Kiswahili in responding to the national examination questions. We are all required to write in English. So at the end of the day students know points for a particular question but the problem is how to write them in examination paper in proper English language (FGD, school E, 18/2/2014).

I think the major factor which contributes to massive failure rate in this school is the use of English language. Many students in the school do not speak English when they find English in Examinations they fail to respond to questions and sometimes they don't even understand the demand of the question. So they end up answering different things from what they have actually been asked (FGD, student, school C, 20/2/2014).

I hate Mathematics because I do not understand it. The teacher uses English in teaching and wants us to ask questions in English while we are not conversant with that language because of our poor foundation of English language when we were in Primary school (FGD, student, school P, 17/4/2014).

I like Kiswahili because it is our national language and I understand the teacher better than I do in subjects taught in English ((FGD, student, school L, 24/2/2014).

\section{Discussion of the Findings}

The findings show that, the majority of students in community secondary schools prefer arts subject. However, this was mainly out of their ability and interests but due to prevailing circumstances in their schools such as shortage of teachers, laboratories and other science teaching and learning facilities. Even the few students who indicated that they like science were unsure that they would do well in the form four national examinations due to the teaching and learning challenges in their schools. These findings suggest that, in the studied schools, what determined the subject selection was the particular school environment. The availability of sufficient resources provided wider opportunities for the students to select subjects they liked while lack of facilities limited students' 
options. In that regard, some students were forced to select subjects that conflicted with their wishes, interests and abilities. It is clear that their preference for either arts or science subjects was largely determined by the availability of teachers and other resources.

Responses of students who participated in the study show that teachers play a significant role in influencing students' tendency to like or dislike a particular subject. Teachers who use student friendly teaching and learning approaches, who are punctual, committed and sensitive to the needs of their students contributed to enhancing students interests in the subjects they were teaching. On the other hand, students indicated that the teachers' poor teaching methods, use of abusive language, lack of commitment, and failure to code switch while teaching contributed towards their dislike of certain subjects. The findings are consistent with [10] who showed that the teaching methods and style, attitude towards the students and relationship with them significantly affect the students' preference for certain subjects.

The availability of teachers and school related factors are among key determining factors in eroding or developing students' interests in particular subjects. The influence of parents was not as pronounced as the influence of teachers possibly due to the nature of the parents in the studied areas. The study findings show that most parents in the community schools have never been to secondary school and have relinquished all responsibility regarding their children's education to the school. Schools with sufficient teachers and resources provided students with wider opportunities to select subjects they liked while those with lack of facilities limited the students' options.

\section{Conclusion and Recommendations}

The findings suggest that there are inequities in terms of how students select subjects in various schools. The evidence from the studied schools shows that students from well-resourced schools were advantageous in the sense that the environment enabled them to decide freely subjects that interested them. The optimum learning environment in their schools facilitated them to excel in all subjects. Thus the decision to select subjects of their focus was based on their interests and ability. However, in Tanzania the majority of the students are enrolled in ward/community secondary schools which have challenges related to the availability of teachers and teaching and learning facilities. As a result, they are denied the opportunity to select subjects according to their wishes, abilities and interests. On the basis of these findings, it is evident that the majority of students from inadequately resourced schools take arts subjects, contrary to their wishes. The problem related to taking subjects that do not interest them may contribute towards massive failure of students in their final examinations. As contented by [1], interest in the subject is the most important motivational factor in learning.

Based on the findings of the study, the following measures are recommended: firstly, the government should create a conducive learning environment, especially in community schools, that will allow students to select subjects on the basis of their ability and interests. This is necessary to ensure that the students are not denied opportunity to study and excel in the subjects of their interest. Secondly, the school authorities should make follow up and collect regularly the students' views regarding teaching and learning for each subject. Most of the problems identified by students, especially those in relation to the teachers, can easily be sorted out with the school authorities. This will allow the students to enjoy the subjects they take and increase the possibility of attaining good performance.

\section{References}

[1] Stefan, M. and Ciomon, F. (2010) The 8th and 9th Grades Students' Attitudes toward Teaching and Learning Physics. Acta Didactics Napocensia, 3, 7-14.

[2] Gardner, P. and Tamir, P. (1989) Interest in Biology. Part I: A Multidimensional Construct. Journal of Research in Science Teaching, 26, 409-423. http://dx.doi.org/10.1002/tea.3660260506

[3] Ministry of Education and Vocational Training (2006) Education Circular No. 1 of 2005 about Curriculum Changes in Secondary Education.

[4] National Examinations Council of Tanzania (2014) Examinations Results Statistics for CSEE 2013. Issued by the Department of Information and Communication Technology, February 21st 2014.

[5] Granström, K. (2006) Group phenomenon and classroom Management. In: Evertson, C.M and Weinstein, C.S., Eds., Handbook for Classroom Management: Research, Practice and Contemporary Issues, Erlbaum, New York, 11411160 . 
[6] Oppendekker, M.C. and Van Damme, J. (2006) Teacher Characteristics and Teaching Styles as Effectiveness Enhancing Factors of Classroom Practice. Teaching and Teacher Education, 22, 1-21.

[7] Yin, R.K. (2008) Case Study Research Designs and Methods. 4rd Edition, SAGE, London.

[8] Miles, B. and Huberman, A. (1994) An Expanded Sourcebook Qualitative Data Analysis. 2nd Edition, SAGE, London.

[9] Lincoln, Y.S. and Guba, G.E. (2000) The Only Generalization Is There Is No Generalization. In: Gomm, R., Hammersley, M. and Foster, P., Eds., Case Study Method, SAGE, London, 27-45.

[10] Akintade, B.O. (2012) Considering the Determinants of selecting Geography as a Discipline: The case of Senior Secondary School Students in Ilorin, Nigeria. Ozean Journal of Social Sciences, 5, 1-8.

[11] Athanasou, J.A. and Petoumenos, K. (1998) Which Components of Instruction Influence Student Interest? Australia Journal of Teacher Education, 23, 61-67. http://dx.doi.org/10.14221/ajte.1998v23n2.5

[12] Samuelsson, J. (2010) The Impact of Teaching Approaches on Students' Mathematical Proficiency in Sweden. International Electronic Journal of Mathematics Education, 5, 61-78.

[13] Wenchao, J., Alastair, M. and Luke, S. (2010) Subject and Course Choices at Ages 14 and 16 amongst Young People in England: Insights from Behavioral Economics. Research Report DFE-RR 160.

https://www.gov.uk/government/uploads/system/uploads/attachment data/file/182677/DFE-RR160.pdf 